

\title{
Modelling the intake of polychlorinated dibenzo-p-dioxins and dibenzofurans: impact of energy under-reporting and number of reporting days in dietary surveys
}

Tero Hirvonen, Harri Sinkko, Anja Hannele Hallikainen, Hannu Kiviranta, Pirjo Pietinen, Liisa Valsta, Jouni T Tuomisto

\section{To cite this version:}

Tero Hirvonen, Harri Sinkko, Anja Hannele Hallikainen, Hannu Kiviranta, Pirjo Pietinen, et al.. Modelling the intake of polychlorinated dibenzo-p-dioxins and dibenzofurans: impact of energy underreporting and number of reporting days in dietary surveys. Food Additives and Contaminants, 2010, 27 (08), pp.1170-1176. 10.1080/19440041003724863 . hal-00604041

\section{HAL Id: hal-00604041 https://hal.science/hal-00604041}

Submitted on 28 Jun 2011

HAL is a multi-disciplinary open access archive for the deposit and dissemination of scientific research documents, whether they are published or not. The documents may come from teaching and research institutions in France or abroad, or from public or private research centers.
L'archive ouverte pluridisciplinaire HAL, est destinée au dépôt et à la diffusion de documents scientifiques de niveau recherche, publiés ou non, émanant des établissements d'enseignement et de recherche français ou étrangers, des laboratoires publics ou privés. 


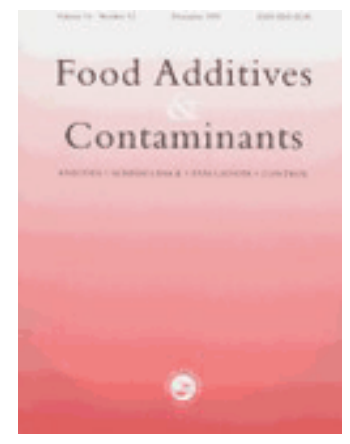

\section{Modelling the intake of polychlorinated dibenzo-p-dioxins and dibenzofurans: impact of energy under-reporting and number of reporting days in dietary surveys}

\begin{tabular}{|c|c|}
\hline Journal: & Food Additives and Contaminants \\
\hline Manuscript ID: & TFAC-2009-398.R1 \\
\hline Manuscript Type: & Original Research Paper \\
\hline $\begin{array}{r}\text { Date Submitted by the } \\
\text { Author: }\end{array}$ & 22-Feb-2010 \\
\hline Complete List of Authors: & $\begin{array}{l}\text { Hirvonen, Tero; Finnish Food Safety Authority Evira, Risk } \\
\text { Assessment Unit } \\
\text { Sinkko, Harri; National Institute for Health and Welfare, } \\
\text { Department of Lifestyle and Participation } \\
\text { Hallikainen, Anja; Finnish Food safety Authority } \\
\text { Kiviranta, Hannu; National Institute for Health and Welfare,, } \\
\text { Department of Environmental Heath } \\
\text { Pietinen, Pirjo; National Institute for Health and Welfare, } \\
\text { Department of Lifestyle and Participation } \\
\text { Valsta, Liisa; National Institute for Health and Welfare, Department } \\
\text { of Lifestyle and Participation } \\
\text { Tuomisto, Jouni; National Institute for Health and Welfare, , } \\
\text { Department of Environmental Heath }\end{array}$ \\
\hline Methods/Techniques: & Exposure - prob modelling, Risk assessment, Survey \\
\hline Additives/Contaminants: & Dioxins \\
\hline Food Types: & Fish and fish products \\
\hline
\end{tabular}

\section{SCHOLARONE $^{\text {TM }}$ Manuscripts}




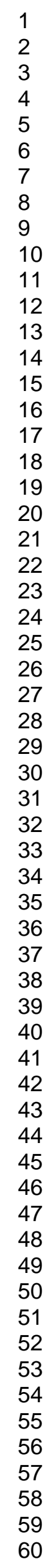 \\ Page 1 of 21}

1

2

4

5

7

8

10

11

12

14

15

16

17

19

20

22

23

25

26

27

29

30

32

33

34

35

36

37

38

41

42

43

44

46

47

48

50

51

53

54

55

57

58

59

60

http://mc.manuscriptcentral.com/tfac Email: fac@tandf.co.uk 
Modelling the intake of polychlorinated dibenzo-p-dioxins and dibenzofurans: impact of energy under-reporting and number of reporting days in dietary surveys

5 Tero Hirvonen ${ }^{1,2}$, Harri Sinkko ${ }^{2}$, Anja Hallikainen ${ }^{1}$, Hannu Kiviranta ${ }^{3}$, Pirjo Pietinen ${ }^{2}$, Liisa Valsta $^{2}$, Jouni T. Tuomisto ${ }^{3}$

${ }^{1}$ Finnish Food Safety Authority, Risk Assessment Unit, Mustialankatu 3, FI-00790 Helsinki, Finland

${ }^{2}$ National Institute for Health and Welfare (THL), Department of Lifestyle and Participation, P.O. 10 Box 30, FI-00271 Helsinki, Finland

${ }^{3}$ National Institute for Health and Welfare (THL), Department of Environmental Health, P.O. Box 90, 70701 Kuopio, Finland

15 Keywords: dioxins, energy under-reporting, intake assessment, dietary surveys 


\begin{abstract}
5 A probabilistic long-term intake estimation of dioxins was carried out using food consumption data obtained from the National FINDIET 2007 Survey. The study population consisted of 606 participants who were first interviewed with a 48-h recall and then filled in a 3-day food record twice. The concentrations of dioxins were obtained from previously published studies. The intake was estimated using a semi-parametric Monte Carlo simulation. The analyses were done

10 separately for the whole study population and for the population excluding energy under-reporters. To diminish the impact of intra-individual variation and nuisance effects, adjustment with software $\left(\mathrm{C}-S I D E^{\circledR}\right)$ was also done after Monte Carlo simulation. It was found that when C-SIDE ${ }^{\circledR}$ was used, the $95^{\text {th }}$ percentile of intake and its confidence limit was higher with 2 reporting days than with a higher number of days. However, with a crude intake estimation (no adjustment), the

15 confidence intervals of the $95^{\text {th }}$ percentile were also smaller with a higher number of days, but the $95^{\text {th }}$ percentiles were higher with a higher number of reporting days. When under-reporters were excluded the intakes increased, but the impact of energy under-reporting was smaller with 8 reporting days than with 2 days and smaller using C-SIDE ${ }^{\circledR}$ than with a crude estimation. To conclude, adjustment for intra-individual variation and taking energy underreporting into account 20 are essential for intake estimation of dioxins with food consumption data of limited number of reporting days.
\end{abstract}




\section{Introduction}

Food of animal origin is the main source of dietary intake to polychlorinated dibenzo- $p$-dioxins and dibenzofurans (dioxins) (Liem et al. 2000). In Finland among foodstuffs the highest

5 concentrations of dioxins are found in fish, especially Baltic Sea fatty fish (Wiborg et al. 2008) (Fig. 1). The effects of dioxins on human health have been studied vigorously during past decades. Based on animal studies and epidemiological human studies adverse health effects include cancer, immunotoxicity, developmental toxicity, and reproductive toxicity (WHO 2000). Public concern about the effects of dioxins on human health have lead to several risk assessments of these

10 compounds, among others one carried out by the European Union Scientific Committee on Food (SCF 2001). Furthermore, not only public concern was the cause of performing risk assessments of dioxins, but also scientific and political concern. Fish on the other hand, is an important source of polyunsaturated marine n-3 fatty acids, vitamin D, vitamin $B_{12}$, and selenium (The National FINDIET 2007 Survey). For benefit/risk assessment of fish consumption, a precise estimation of 15 intake of dioxins is essential. For dioxins - as for most of the contaminants - the chronic intake is the most important issue in the risk assessment. Therefore, the usual (long term) intake of dioxins was estimated.

In order to be valid, the intake estimation of contaminants should be based on demographically representative food consumption data (Kroes et al. 2002). However, such data are 20 usually not collected primarily for the purpose of intake assessment of contaminants, but for nutritional epidemiology purposes or for dietary monitoring purposes. Nutrients usually have several sources of intake and their variation in concentration is relatively small. In addition, average intake, either for the population or at an individual level, is in most cases a sufficient level of information for nutrients. For contaminants the opposite is true: sources of individual 25 contaminants are usually few and in food there is a great variance in contaminant concentration. In 
addition, for risk assessment purposes, the average intake is not sufficient, but the higher end of the intake distribution should be estimated, including parameters like the $95^{\text {th }}$ percentile. The task is very challenging, as the dietary data usually cover only one or two reporting days. Furthermore, if only few reporting days are available, the intra-individual variation in food consumption is

5 usually overestimated. However, software has been developed to take into account the intraindividual variation (removes the extra intra-individual variation caused by measurement error) and nuisance effects (e.g. day of the week, interviewer) in nutritional surveys (Dodd et al. 2006) and these could also be used for other substances than nutrients. The impact of the number of reporting days on contaminant intake has not, to our knowledge, been investigated earlier. consumption is not sufficient to cover the energy expenditure (Maurer et al. 2006). It is due either to misreporting of the diet or by restriction of the energy intake during the reporting period (e.g. food record). It is a serious problem in nutritional epidemiology that does not affect only the energy intake estimates, but all nutrients and foods (Hirvonen et al. 1997, Stallone et al. 1997, 15 Cook et al. 2000). The impact of energy under-reporting on contaminant intake has not, to our knowledge, been investigated previously.

In this study, we assessed the impact of energy under-reporting and the number of reporting days in dietary surveys on the dioxin intake. In addition, we examined the impact of software that aims at decreasing the impact of intra-individual variation and nuisance effects (e.g. 20 day of the week, interviewer).

\section{Materials and methods}

Data on food consumption were obtained from the National FINDIET 2007 Survey, carried out as part of the FINRISK 2007 Study which monitors cardiovascular risk factors (Fig. 2), (The 25 National FINDIET 2007 Survey ). A random sample of 9, 958 persons aged 25-74 years in five 
areas, stratified by sex, area, and 10-year age groups, was taken from the population register. The study areas were: (1) Helsinki area; (2) the city of Turku and some rural municipalities in SouthWestern Finland; and the provinces of (3) North Karelia, (4) North Savo and (5) Oulu. The participation rate was $63 \%$, i.e. 6,259 subjects. Of these, 2,069 persons were invited to participate 5 in the FINDIET Study.

Participants were interviewed using the 48-h dietary recall between January and March. The 48-h recall data consisted of all days except Fridays. A subsample of the participants filled in a 3-day food record twice: the first starting the day after the 48-h recall in January-March and the second in June-December (Fig. 2). The National Food Composition Database FINELI ${ }^{\circledR}$ 10 (www.fineli.fi) was used to calculate the food consumption. The content of dioxins of foods has been determined in national food monitoring surveys during 2002 and 2005 (Isosaari et al. 2006; Wiborg et al. 2008). The dioxin content in foods in these publications were expressed as PCDD equivalents.

The long-term intake of dioxins was estimated by multiplying the food consumption 15 (g/day) by respective dioxin content ( $\mathrm{pg} / \mathrm{g}$ ) for all reporting days. The multiplication was done using bootstrapping (semiparametric Monte Carlo simulation), where food consumption data were treated as constant (Iman \& Conover 1982). Bootstraping was used in the intake estimation of both crude (C-SIDE not used) and adjusted (C-SIDE used) results. Therefore, bootstrapping was done for concentration data only. Bootstrapping was done only on 400 rounds because it was a time20 demanding procedure. We used bootstrapping because concentration data has single foods with a small number of values. In this case, estimation of theoretical distribution could be unreliable for a single food concentration. Medians produced from 400 point estimates and confidence intervals of parameters were calculated directly from the bootstrapped data when no adjustment was used (crude results) and from the usual intake distributions when adjustment (C-SIDE) was used. 
The impact of energy under-reporting on intake of dioxins was investigated by estimating the intakes both with under-reporters and without under-reporters. Energy underreporters were excluded using 1.00*BMR (basal metabolic rate) as a cut-off point (Goldberg et al. 1991).

The impact of intra-individual variation and nuisance effects on intake of dioxins was assessed by comparing the results adjusted for intra-individual variation and nuisance effects with non-adjusted results. This adjustment was done after probabilistic (bootstrapping) intake estimation. The adjustment was done using the method of Nusser and co-workers (Nusser et al.1996). This method gives the long-run average of daily intakes (usual daily intake) by taking 10 into account day-to-day correlation and nuisance effects (such as day-of-week and interview sequence). It also allows exceptions from normality through grafted polynomial transformations and recognizes the measurement error associated with one-day dietary intakes. The estimations were done using the SAS based C-SIDE ${ }^{\circledR}$ program. All the analyses were done separately for men and for women, because men and women have different food consumption patterns (The National 15 FINDIET Study 2007).

\section{Results}

The most important sources of intake of dioxins for both males and females were fish, especially Baltic herring and salmon (Table 1). The total daily intake of dioxins for men was $0.71 \mathrm{pg}$ WHOTEQ/kg bw and $0.47 \mathrm{pg}$ WHO-TEQ/kg bw for women. The contribution of fish to the total intake was $94 \%$ and $91 \%$ for men and women, respectively.

Of all participants, $36 \%$ of men and $39 \%$ of women were identified as energy underreporters. The mean (standard deviation) energy intake in all males was $9000 \mathrm{~kJ}(2210 \mathrm{~kJ})$ and in all females $7050 \mathrm{~kJ}(1610 \mathrm{~kJ})$. Among under-reporters the mean energy intake was $6970 \mathrm{~kJ}(1110$ $\mathrm{kJ})$ in males and $5630 \mathrm{~kJ}(899 \mathrm{~kJ})$ in females. The Spearman correlations between intake of 
dioxins and energy were in all males 0.15 and in females 0.02. Among under-reporting males the correlation was -0.04 and in females 0.02 .

When no adjustments for intra-individual variation or nuisance effects were done (crude results), in males confidence limits of the $95^{\text {th }}$ percentile of intake of dioxins were higher

5 for three reporting days than for two reporting days, but tended to diminish with higher number of reporting days (Table 2). For females, the $95^{\text {th }}$ percentile of intake and their confidence limits tended to increase with increasing reporting days. The impact of excluding energy under-reporters among males was largest with three reporting days on intake of dioxins, but decreased with increasing number of reporting days for crude results. In females, the impact of under-reporters 10 was negligible, but increased during the second record period. For median intakes the impact of number of days or energy under-reporting was small.

When the adjustment for intra-individual variation and nuisance effects was done, the $95^{\text {th }}$ percentile of intake and its confidence limit was higher with 2 reporting days than with a higher number of days and both $95^{\text {th }}$ percentiles and their confidence limits diminished

15 monotonically in men with an increasing number of reporting days for both males. In women, however, the impact of number of reporting days was smaller (Table 2). The impact of excluding energy under-reporters diminished with increasing reporting days. In addition, for males the median intakes and their confidence limits diminished with increasing reporting days. In females, both energy under-reporting and number of reporting days had negligible impact on median 20 intakes.

\section{Discussion}

In the present study, we found that the high number of reporting days had a great effect on the dioxin intake estimates, especially by narrowing the confidence intervals after adjustment for 25 intra-individual variation and nuisance effects by software. In addition, adjusting for nuisance 
It is clear that two consecutive reporting days is not enough to estimate the intake of dioxins or any other contaminant - especially if the higher end of the intake is of interest. However, it is not clear how many days are enough to estimate contaminant intake. There

10 probably is a trade-off between the costs of additional days and accuracy of estimates.

Furthermore, the sufficient accuracy in turn depends on the margin of exposure of the contaminant, i.e. if exposure is likely to be near the tolerable intake level, then the accuracy should be higher than with a compound with higher margin of exposure. The number of reporting days depends also on the food consumption pattern, since sources of contaminants vary greatly

15 culturally. If too few days are used, the intake of dioxins is overestimated and the risk for excessive intake is also overestimated, especially when adjustment for intra-individual variation and nuisance effects are made. The number of reporting days is also a question of participant compliance: participation could drop dramatically if the work load of the participants is increased. For example, in this study, $88 \%$ of the participants returned the first food record, but only $65 \%$ 20 also returned the second food record (The National Findiet 2007 Survey, 2008).

In addition to number of reporting days, it is also important that all days are not consecutive, since a low number of only consecutive days could result artificially to low intraindividual variation in food consumption and contaminant intake. This phenomenon was also seen in this study: only two consecutive days gave smaller confidence intervals than higher number of non-consecutive days. For nutrients two non-consecutive days are estimated to be sufficient for 
monitoring purposes (Hoffmann et al 2002). However, when the number of consecutive days is high enough (e.g. one week), the intra-individual variation is probably captured.

The fact that non-adjusted intakes were much higher than adjusted intakes when reporting days were increased is surprising and should be studied further. However, the confidence 5 limits diminished monotonically in adjusted intakes, whereas in non-adjusted intakes the standard error did not change. This is an expected result, since the software is able make use of the increased amount of measurements per individual. This and adds assurance that the programme functions properly. When these quite divergent results are taken together, it could be concluded that the software is useful in decreasing the intra-individual variation, but it is clear that the 10 software cannot correct for insufficient number of reporting days.

Adjusting for intra-individual variation and nuisance effects by using software seems to be an efficient way to diminish the confidence limits of the $95^{\text {th }}$ percentiles and to decrease the impact of energy under-reporting. We did not, however, validate our results against a golden standard method (e.g. adipose tissue concentration of dioxins). Therefore, it is difficult to say 15 whether a decrease in the intra-individual variation is in accordance with the reality. Therefore, more research - both theoretical and practical - is needed to find out the role of intra-individual variation and energy under-reporting on contaminant intake estimation.

Energy under-reporting does not seem to be of great concern in the estimation of dioxin intake, especially if the number of reporting days is sufficient and if methods to adjust for 20 intra-individual variation and nuisance effects are used. This is not surprising, since in a Finnish study it was found that foods that are considered healthy are under-reported less or are even overreported (Hirvonen et al. 1997). Fish in Finland is considered to be healthy and therefore it is probably not under-reported to a great extent. On the other hand, in an American study fish was not under-reported to a lesser extent than other foods (Krebs-Smith et al. 2000). In fact, in this 25 study the qualitative differences in under-reporting were in all rather small. The differences in the 
Finnish and the American study could be partly related to cultural factors and partly to the fact that in the Finnish study the method to measure food consumption was a 48-h recall and a 3-day food record whereas in the American study a food frequency questionnaire was used. The fact that under-reporting affected women less than men (at least in terms of absolute intake), even though

5 women are in general more prone to under-report (Maurer et al.2006), is surprising. Perhaps this has to do with higher health consciousness of women - they are more aware than men that fish is considered healthy and therefore, probably under-reported fish less or even overreport fish consumption.

However, it should be kept in mind that using $1.0 * \mathrm{BMR}$ as a cut-off point for under-

10 reporting is a rather low limit and therefore excludes only the extreme energy under-reporters. Using a higher cut-off level, however, would not be justifiable, since due to high inter-individual variation in the basal metabolic rate (Shetty 2005), part of the population has a very low basal metabolic rate and excluding them is not correct. As a consequence, the data still probably contain some bias caused by energy under-reporting.

The present study shows that the sources of intra-individual differences (e.g. temporal variation) should be taken into account when food consumption studies that are used for intake estimation of contaminants are planned. This underlines the co-operation between those estimating contaminant intake and those who plan and carry out dietary surveys. In fact, precise calculations are needed to estimate the number of reporting days for the contaminants or other non-nutrient substances to be estimated prior to a dietary survey. The risk can only be estimated when the high intake levels can be compared to reference levels, e.g. tolerable daily intake.

Could some other food consumption method be used to estimate contaminant intake in order to avoid the problems with 24/48-h recalls or food records? A food frequency questionnaire would be an appealing alternative because of its convenience both for the 25 investigator and for the participant. However, for each group of contaminants a separate food 
frequency questionnaire should be planned and validated separately. This is seldom feasible, since this process is time consuming and costly. In addition, food frequency questionnaires are not suitable for estimating absolute intakes, but are to group people into low and high intake groups (Willett 1998). The other problem with food frequency questionnaires is often energy over-

5 reporting rather than under-reporting. However, these problems can partly be overcome by asking a small part of the participants (who fill also food frequency questionnaire) to fill in also dietary records. Dietary records could then be used to calibrate e.g. portion sizes and energy intake. Another alternative to dietary recalls or food records would be dietary history. The problem with the low number of reporting days would be avoided, since dietary history aims at forming an 10 overall view of the participant's diet. However, dietary history has probably also the problem of energy under-reporting, since dietary history is usually started with a $24-\mathrm{h}$ recall. In addition, dietary history is very time consuming both for study personnel and participants and therefore also costly.

Our results are not directly generalizable to other populations or to other

15 contaminants or other substances, since energy under-reporting patterns and sources of contaminants vary between populations and population groups (e.g. children). However, with a high number of reporting days the intake estimates of any contaminant in any population are probably more accurate than with a low number. In addition, estimating contaminant intake also but not solely - excluding under-reporters is useful and gives a rough estimate of the impact of 20 under-reporting on results.

In conclusion, intra-individual variation and nuisance effects may have a large impact on contaminant intake estimates. In addition, by estimating the intake both with underreporters and without under-reporters the impact of energy under-reporting could be assessed. Furthermore, one 48 -h recall is not sufficient to estimate the intake of a contaminant. However, 
with software that adjusts for intra-individual variation and nuisance effects, the effect of intraindividual variation and energy under-reporting could be decreased.

\section{Acknowledgement}

This study was funded by the EU-funded project BENERIS. 


\section{References}

Cook A, Pryer J, Shetty P.2000 The problem of accuracy in dietary surveys: analysis of the over 65 UK national Diet and Nutrition Survey. J Epidemiol Community Health 54:611-6.

Dodd KW, Guenther PM, Freedman LS, Subar AF, Kipnis V, Midthune D, Tooze JA, KrebsSmith SM. 2006. Statistical methods for estimating usual intake of nutrients and foods: a review of the theory. J Am Dietetic Assoc106:1640-50.

10 Goldberg GR, Black AE, Jebb SA, Cole TJ, Murgatroyd PR, Coward WA, Prentice AM. 1991.

Critical evaluation of energy intake data using fundamental principles of energy physiology: 1 .

Derivation of cut-off limits to identify under-recording. Eur J Clin Nutr 45:569-81.

Hirvonen T, Männistö S, Roos E, Pietinen P. 1997. Underreporting does not distort dietary 15 surveys. Eur J Clin Nutr 51:297-301.

Hoffmann K, Boeing H, Dufour A, Volatier JL, Telman J, Virtanen M, Becker W, De Henauw S. Estimating the distribution of usual dietary intake by short-term measurements. Eur J Clin Nutr 2002;56:S53-S62.

Iman RL, Conover WJ. 1982. A Distribution-Free Approach to Including Rank Correlation Among Input Variables. Communications in Statistics: Simulations and Computations. 11: 311334. 
Isosaari P, Hallikainen A, Kiviranta H, Vuorinen PJ, Parmanne R, Koistinen J, Vartiainen T. 2006. Polychlorinated dibenzo- $p$-dioxins, dibenzofurans, biphenyls, naphthalenes and polybrominated diphenyl ethers in the edible fish caught from the Baltic Sea and lakes in Finland. Environmental Pollution 141: 213-225.

5

Krebs-Smith SM, Graubard BI, Kahle LL, Subar AF, Cleveland LE, Ballard-Barbash R. 2000. Low energy reporters vs others: a comparison of reported food intakes. Eur J Clin Nutr 54:281-7.

10 Kroes R, Müller D, Lambe J, Löwik MRH, van Klaveren J, Kleiner J, Massey R, Mayer S, Urieta I, Verger P, Visconti A. 2002. Assessment of intake from diet. Food \& Chem Toxicol 40:327-85.

Liem AKD, Furst P, Rappe C. 2000. Exposure of populations to dioxins and related compounds. Food Addit and Contam 17: 241 - 259.

Maurer J, Taren DL, Teixeira PJ, Thompson CA, Lohman TG, Going SB, Houtkooper LB. 2006.

The psychosocial and behavioral characteristics related to energy misreporting. Nutr Rev 64:5366.

The National FINDIET 2007 Survey. 2008. Paturi M, Tapanainen H, Reinivuo H, Pietinen P (eds.). Publications of the National Public Health Institute B 23/2008.

25 Nusser SM, Carriquiry AL, Dodd KW, Fuller WA. 1996. A semiparametric transformation approach to estimating usual daily intake distributions. J. Am. Stat. Assoc. 91:1440-9.

SCF. 2001. Update of the "Risk assessment of dioxins and dioxin-like PCBs in food" based on 30 new scientific information available since the adoption of the SCF opinion of $22^{\text {nd }}$ November 
2000; Opinion of the Scientific Committee on Food, adopted on 30 May 2001. European

Commission Health and Consumer Protection Directorate-General.

Shetty P. 2005. Energy requirements of adults. Public Health Nutr 8: 994-1009.

5

Stallone DD, Brunner EJ, Bingham SA, Marmot MG. 1997. Dietary assessment in Whitehall II: the influence of reporting bias on apparent socioeconomic variation in nutrient intakes. Eur J Clin Nutr 51:815-25.

10 WHO Temporary Advisers. 2000. Consultation on assessment of the health risk of dioxins; reevaluation of the tolerable daily intake (TDI): executive summary. Food Addit Contam 17: 223240.

Wiborg ML, Knutsen HK, Andersson Ö, Büchert A, Cederberg T, Darnerud PO, Hallikainen A,

15 Kiviranta H, Ólafsdóttir K, Petersen K, Rajakangas L, Sletta A. 2008. EU maximum levels for dioxins and dioxin-like PCBs - Impact on exposure and food supply in the Nordic countries. TemaNord 2008: 531. 


\section{Legends to figures}

Figure 1. Concentration of dibenzo- $p$-dioxins and dibenzofurans (WHO-TEQ) in foodstuffs. BS= Baltic sea, IL=inland water.

5

Figure 2. Flow chart of the study. In all intake estimations bootstrapping (probabilistic method) was used. 


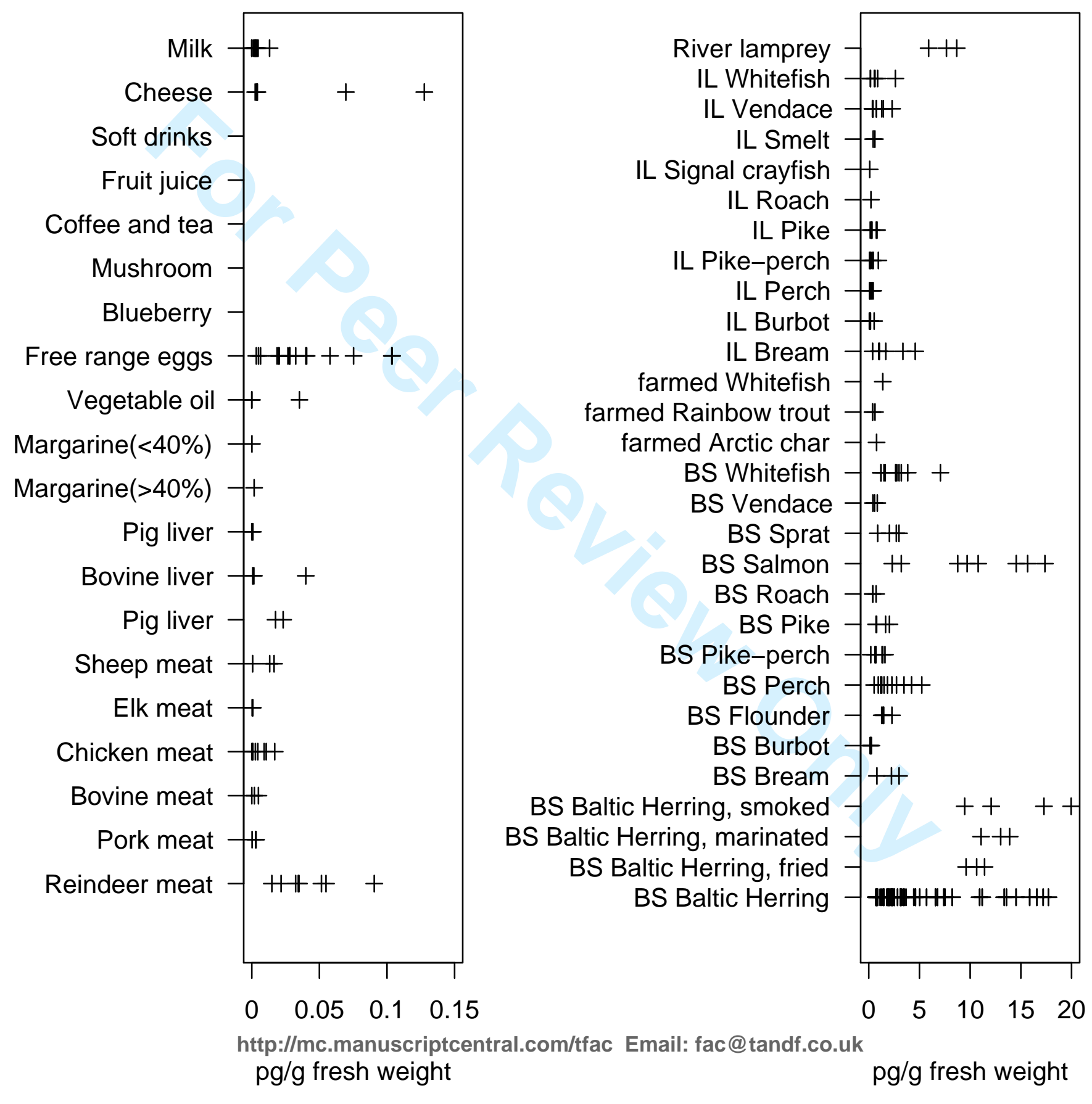


Stratified random sample in 5 areas $(\mathrm{n}=9958)$ invited to FINRISK Study



2nd food record sent by post: $n=937$

Acceptable $2^{\text {nd }}$ food record returned: $\mathrm{n}=606(65 \%)$

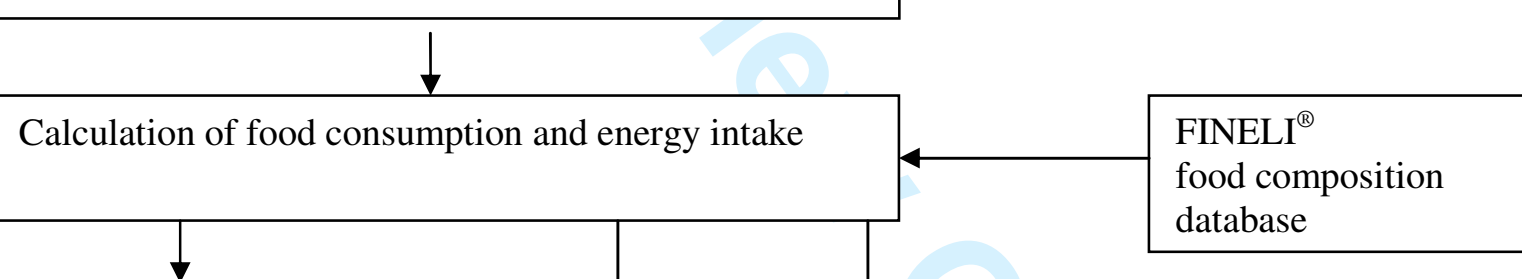

Concentration of PCDD/F compounds in foods (Isosaari et al. 2006; Wiborg et al. 2008) 
Table 1. Sources of PCDD/F compounds (intake of WHO-TEQ) by sex.

\begin{tabular}{|l|c|c|c|c|}
\hline & \multicolumn{2}{|l|}{ Men } & \multicolumn{2}{l|}{ Women } \\
\hline & $\begin{array}{l}\mathrm{pg} / \mathrm{kg} \\
\text { bw/day }\end{array}$ & $\%$ & $\begin{array}{l}\mathrm{pg} / \mathrm{kg} \\
\text { bw/day }\end{array}$ & $\%$ \\
\hline Baltic Herring & 0.2491 & 35.12 & 0.1444 & 30.61 \\
\hline Salmon & 0.1893 & 26.69 & 0.1178 & 24.97 \\
\hline Farmed Rainbow trout & 0.0468 & 6.60 & 0.0530 & 11.24 \\
\hline Unknown smoked fish, high fat & 0.0382 & 5.38 & 0.0425 & 9.02 \\
\hline Whitefish & 0.0366 & 5.15 & 0.0135 & 2.85 \\
\hline Bream & 0.0312 & 4.40 & 0.0076 & 1.61 \\
\hline Vendace & 0.0291 & 4.10 & 0.0165 & 3.49 \\
\hline Unknown fish & 0.0198 & 2.79 & 0.0144 & 3.05 \\
\hline Cheese & 0.0126 & 1.78 & 0.0139 & 2.94 \\
\hline Perch & 0.0118 & 1.67 & 0.0097 & 2.05 \\
\hline Eggs & 0.0111 & 1.56 & 0.0110 & 2.33 \\
\hline Pike & 0.0088 & 1.23 & 0.0023 & 0.49 \\
\hline Milk & 0.0073 & 1.03 & 0.0076 & 1.61 \\
\hline Flounder & 0.0051 & 0.71 & 0.0056 & 1.18 \\
\hline Chicken & 0.0047 & 0.66 & 0.0048 & 1.02 \\
\hline Saithe & 0.0021 & 0.30 & 0.0022 & 0.47 \\
\hline Game & 0.0016 & 0.23 & 0.0010 & 0.22 \\
\hline Pork & 0.0016 & 0.22 & 0.0011 & 0.24 \\
\hline Berries & 0.0011 & 0.16 & 0.0016 & 0.33 \\
\hline Other & 0.0016 & 0.22 & 0.0013 & 0.28 \\
\hline Total & $\mathbf{0 . 7 1}$ & $\mathbf{1 0 0}$ & $\mathbf{0 . 4 7}$ & 100 \\
\hline
\end{tabular}


Table 2. Intake of PCDD/F compounds (WHO-TEQ as $\mathrm{pg} / \mathrm{kg}$ bw/day) in crude and adjusted estimations by sex, number of reporting days, and under-reporting,

\begin{tabular}{|c|c|c|c|c|c|c|}
\hline & & & \multicolumn{2}{|l|}{ All $(n=606)$} & \multicolumn{2}{|c|}{ Under-reporters excluded $(n=365)$} \\
\hline & & days & Median $(\mathrm{Cl})$ & $95 \%(\mathrm{Cl})$ & Median $(\mathrm{Cl})$ & $95 \%(\mathrm{Cl})$ \\
\hline \multirow[t]{14}{*}{ Men } & \multirow{7}{*}{$\begin{array}{r}\text { Crude } \\
\text { estimation }\end{array}$} & 2 & $0.05(0.05-0.06)$ & $2.06(1.65-2.62)$ & $0.06(0.05-0.06)$ & $2.25(1.65-3.09)$ \\
\hline & & 3 & $0.07(0.07-0.08)$ & $2.78(2.04-3.84)$ & $0.09(0.08-0.10)$ & $3.88(2.64-5.71)$ \\
\hline & & 4 & $0.09(0.08-0.10)$ & $2.55(1.93-3.58)$ & $0.13(0.11-0.14)$ & $3.44(2.39-4.95)$ \\
\hline & & 5 & $0.11(0.10-0.12)$ & $2.58(2.03-3.34)$ & $0.16(0.14-0.18)$ & $3.35(2.50-4.41)$ \\
\hline & & 6 & $0.15(0.13-0.17)$ & $2.79(2.16-3.46)$ & $0.23(0.20-0.27)$ & $3.37(2.41-4.33)$ \\
\hline & & 7 & $0.21(0.19-0.23)$ & $2.96(2.39-3.69)$ & $0.29\left(\begin{array}{lll}0.26 & 0.32) \\
\end{array}\right.$ & $3.33(2.61-4.46)$ \\
\hline & & 8 & $0.24(0.21-0.26)$ & $2.97(2.48-3.78)$ & $0.33(0.27-0.36)$ & $3.27(2.60-4.28)$ \\
\hline & \multirow{7}{*}{$\begin{array}{l}\text { Adjusted } \\
\text { estimation }\end{array}$} & 2 & $0.30(0.21-0.45)$ & $1.90(1.34-2.54)$ & $0.30(0.21-0.46)$ & $2.47(1.58-4.25)$ \\
\hline & & 3 & $0.31(0.24-0.39)$ & $1.13(0.83-1.49)$ & $0.33(0.26-0.45)$ & $1.54(1.00-2.47)$ \\
\hline & & 4 & $0.30(0.25-0.37)$ & $1.07(0.83-1.34)$ & $0.31(0.24-0.42)$ & $1.37(0.88-1.99)$ \\
\hline & & 5 & $0.30(0.23-0.37)$ & $1.04(0.81-1.28)$ & $0.31(0.25-0.39)$ & $1.19(0.90-1.51)$ \\
\hline & & 6 & $0.29(0.23-0.37)$ & $0.92(0.73-1.12)$ & $0.31(0.25-0.41)$ & $1.05(0.80-1.28)$ \\
\hline & & 7 & $0.28(0.23-0.36)$ & $0.87(0.69-1.09)$ & $0.30(0.23-0.41)$ & $1.03(0.79-1.26)$ \\
\hline & & 8 & $0.28(0.23-0.34)$ & $0.86(0.69-1.05)$ & $0.29(0.23-0.40)$ & $0.99(0.79-1.21)$ \\
\hline \multirow[t]{14}{*}{ Women } & \multirow{7}{*}{$\begin{array}{r}\text { Crude } \\
\text { estimation }\end{array}$} & 2 & $0.05(0.05-0.05)$ & $1.27(1.08-1.47)$ & $0.06(0.05-0.07)$ & $1.38(1.08-1.76)$ \\
\hline & & 3 & $0.07(0.06-0.08)$ & $1.44(1.20-1.78)$ & $0.08(0.07-0.09)$ & $1.56(1.28-1.90)$ \\
\hline & & 4 & $0.09(0.08-0.10)$ & $1.74(1.42-2.07)$ & $0.10(0.09-0.11)$ & $1.81(1.37-2.25)$ \\
\hline & & 5 & $0.11(0.10-0.12)$ & $1.78(1.50-2.11)$ & $0.13(0.12-0.14)$ & $1.74(1.47-2.26)$ \\
\hline & & 6 & $0.13(0.12-0.14)$ & $1.95(1.62-2.46)$ & $0.14(0.13-0.16)$ & $1.70(1.32-2.22)$ \\
\hline & & 7 & $0.14(0.13-0.15)$ & $1.96(1.56-2.37)$ & $0.15(0.13-0.16)$ & 1.66 (1.34-2.22) \\
\hline & & 8 & $0.16(0.16-0.18)$ & $2.09(1.72-2.60)$ & $0.17(0.16-0.18)$ & $1.88(1.37-2.55)$ \\
\hline & \multirow{7}{*}{$\begin{array}{r}\text { Adjusted } \\
\text { estimation }\end{array}$} & 2 & $0.23(0.20-0.27)$ & $1.03(0.65-1.82)$ & $0.30(0.23-0.39)$ & $1.15(0.75-1.65)$ \\
\hline & & 3 & $0.24(0.21-0.29)$ & $0.81(0.61-1.12)$ & $0.32(0.27-0.38)$ & $0.94(0.64-1.42)$ \\
\hline & & 4 & $0.28(0.24-0.36)$ & $0.83(0.64-1.07)$ & $0.35(0.29-0.43)$ & $0.97(0.68-1.33)$ \\
\hline & & 5 & $0.27(0.23-0.32)$ & $0.82(0.66-1.06)$ & $0.33(0.28-0.40)$ & $0.92(0.72-1.20)$ \\
\hline & & 6 & $0.29(0.25-0.33)$ & $0.80(0.66-1.02)$ & $0.35(0.29-0.42)$ & $0.94(0.73-1.21)$ \\
\hline & & 7 & $0.30(0.26-0.35)$ & $0.82(0.68-1.04)$ & $0.37(0.31-0.44)$ & $0.98(0.76-1.27)$ \\
\hline & & 8 & $0.30(0.26-0.35)$ & $0.80(0.65-1.04)$ & $0.38(0.32-0.45)$ & $0.99(0.77-1.28)$ \\
\hline
\end{tabular}

